\title{
Mathematical Modelling for the Thermal Performance of a Solar Parabolic Trough Concentrator (PTC) Under Egypt Climate
}

\author{
Mohamed H. Ahmed ${ }^{a, *}$, Alberto Giaconia ${ }^{b}$, Amr. M. A. Amin ${ }^{c}$ \\ ${ }^{a}$ Solar Energy Department, National Research Centre, Dokki, Giza, Egypt \\ ${ }^{b}$ Energy Technologies Department, ENEA Casaccia Research Center, Roma, Italy \\ ${ }^{c}$ Academy of Scientific Research and Technology, Cairo, Egypt
}

\begin{abstract}
In this work, an analysis of the annual performance of a parabolic trough concentrator has been accomplished. A numerical model was developed and built to study the annual performance of the parabolic trough collector's field at different locations in Egypt. The energy equations were solved using the Engineering Equation Solver EES software. The optical and thermal parameters of the concentrator were considered in the model. The numerical model results showed that temperature rise ranges from 90.5 to $221{ }^{\circ} \mathrm{C}$ and the outlet temperate ranges from 442 to $565{ }^{\circ} \mathrm{C}$ at solar noon according to the season and the location. The operating period of the parabolic concentrator reaches its maximum value at summer where it ranges from 76.5 to $82 \mathrm{~h} /$ week. The present model was validated with the TRNSYS model. As a result, the presented model can be considered as a meaningful tool for developing the parabolic trough plant in Egypt.
\end{abstract}

Keywords: Solar Plant, Numerical Model, Parabolic Trough Collector, Collector Efficiency, Annual Performance, Model Validation

\section{Introduction}

The trend towards the use of solar energy in electricity generation started to grow in recent decades. The solar concentrators especially the parabolic trough collectors (PTC) are an appropriate type of solar collectors to obtain high temperature that is required for electric generation in solar power plants. Several concentrator solar power plants CSP have been successfully operated in the range from 300 to 400 ${ }^{\circ} \mathrm{C}$. The new CSP plants use the progress of selective surfaces, vacuum technology, manufacturing processes, and new materials to improve the efficiency of the solar concentrator and reduce the energy cost. The performance of parabolic trough collectors is greatly affected by its design, constructions, and material used. The structure of parabolic trough was developed to study the deflection of the structure and the optical properties under different wind load conditions [1]. Several parameters affect the parabolic trough collector and the optical efficiency such as the quality of the reflective mirrors, slope error, assembly of the collector components like the absorber tube alignment and structure with mirror supports.
Many of the published papers have focused on the numerical modeling of parabolic trough collector (PTC). Therefore, to recognize the work already done and published by other authors, and especially, to benefit from the already proposed modeling approaches, a literature review has been done and summarized in the following section.

Back in 1976, Edenburn [2] developed a PTC performance model that used detailed 1-dimensional steady state heat transfer equations to different parts of the heat collector element by neglecting the thermal resistance of the envelope, as well as that of the absorber tube. Clark [3] identified the factors that affect the PTC performance, which include the reflectivity of the mirror, the parabola structure, tracking errors, incident angle, the absorptivity of the receiver tube, receiver tube misalignment, intercept factor and the heat losses from the receiver. Lippke [4] published a part-load model of a typical 30 MW SEGS (Solar Energy Generating Systems) plant, located at Kramer Junction, California, USA. A similar PTC solar collector field model was investigated by Jones et al. [5]. Patnode [6] published a comprehensive quasi-steady-state model of the SEGS VI plant. The model used a linear regression equation for the heat loss, based on the detailed

${ }^{*}$ Corresponding author. Tel.: +201005291830

Fax:+9876543210; E-mail: mo555as@hotmail.com

(C) 2018 International Association for Sharing Knowledge and Sustainability

DOI: $10.5383 /$ ijtee.17.01.006 
work of Forristall [7]. Numerical studies for studying wind flow around solar collectors are rare. A turbulent model developed based on resolving the Reynolds averaged NavierStokes equations (RANS) to analyze the fluid flow and heat transfer around a parabolic trough solar collector from Shiraz solar power plant [8]. The recirculation regions around the collector were investigated for different configurations. Also, the Nusselt number around the receiver tube was calculated [9]. Rolim et al. [10] presented an analytical steady-state model for a PTC solar power plant, based on an analysis closed form solution for the non-linearity of the temperature profile the focus line of the parabolic trough concentrator, which was originally published by Fraidenraich et al. [9]. Bergmann et al. [11] presented a dynamic performance model for PTC plant using a so-called "time-series" method, with a constant time step size. The PTC loop, consisting of 6 solar collectors of 150 $\mathrm{m}$ length in series, was arranged in 6 sections, i.e. each modeled section corresponded to one collector. They used empirical correlation for the efficiency for each section. More detailed transient performance model was written by Spelling et al. [12]. They included the glass envelope of the HCE in their PTC model and solved the governing coupled partial differential equations numerically by applying an implicit formulation of the finite difference technique to ensure stability for time steps higher than $5 \mathrm{~min}$. The thermal loss by radiation and convection of heat collecting element (HCE) and also called the receiver tube was calculated and investigated by a simulation program at a different mass flow rate and wind speed using the CFD code ANSYS fluid environment with the assumption of a uniform solar flux around the absorber tube [13]. Odeh et al. [14] have performed a numerical study to estimate the PTC performance for direct steam generation. The model has been based on the absorber tube wall temperature instead of fluid bulk temperature. The effect of the annular pressure between the absorber tube and the glass cover of the receiver tube on the tube performance was investigated by Ahmed [15]. The investigating included the amount of energy gained, the temperature rise of the heat transfer fluid (HTF), energy losses and efficiency.

The purpose of this paper is studying numerically the thermal performance of a parabolic trough collector (PTC) field for a solar power plant at different locations in Egypt using the Engineering Equation Solver (EES) software. The effect of the meteorological parameters on the performance of the PTC field at different flow rates was investigated in this work. The monthly energy gained, temperature rise, outlet temperature and the operating period were calculated for different selected locations. The receiver tube has been divided into two parts, the first is the irradiated part that is subjected to the concentrated radiation reflected from the parabolic mirror and the second part is the non-irradiated part that is subjected to the direct incident radiation from the sun only. The energy and heat balance equations for the HTF and the absorber tube and the glass cover of the receiver tube were applied to each part. These equations were solved using the EES software. The results for the thermal performance of the PTC are presented for different seasons and locations in Egypt.

\section{System Description}

The solar concentrator field concentrates the solar radiation on a heat collecting element (HCE), called receiver tube, with parabolic trough mirror assemblies arranged in a linear system. The solar field has three loops, each loop consists of 6 parabolic trough collectors connected in series, the total length of each loop is $600 \mathrm{~m}$ and the total aperture area is $10348 \mathrm{~m}^{2}$ for the three loops. The concentration ratio of the parabolic trough concentrator (parabolic width divided by the outer diameter of the stainless steel tube) is 98 . The arrangement of the parabolic trough collectors in the solar field is illustrated in Fig. 1. The specifications and dimensions of the solar field are tabulated in Table 1. The parabolic trough collector tracks the sun by a solar tracking system with a North-South tracking axis. The mirror reflects the solar radiation to the focal line of the parabola where the receiver tube is located. This assembly leads to increasing the temperature of the receiver tube consequently the HTF temperature due to the heat transfer between the absorber tube and the HTF. The solar field is provided with a stratified storage tank. A centrifugal variable speed pump was used to move the HTF through the concentrator loops. Using molten salt (a mixture of $60 \%$ $\mathrm{NaNO}_{3}$ and $\left.40 \% \quad \mathrm{KNO}_{3}\right)$ as a HTF has many obvious advantages. With the molten salt, it may be possible to raise the outlet temperature from the solar loop up to $550{ }^{\circ} \mathrm{C}$, thereby increasing the Rankin cycle efficiency of the power block steam turbine to be around $40 \%$. The molten salt flow rate ranges from 14 to $22 \mathrm{~kg} / \mathrm{s}$.

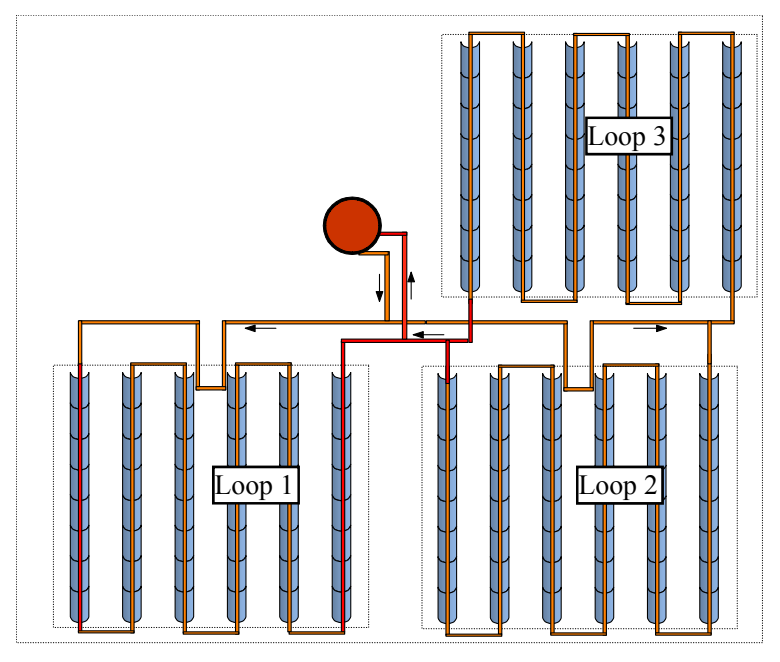

Fig. 1. The layout of the solar concentrator field

Table 1. Specific parameters of the parabolic trough collector field

\begin{tabular}{lll}
\hline Parameters & Value & Unit \\
Parabola width & 5.9 & $\mathrm{~m}$ \\
Parabola length & 12.18 & $\mathrm{~m}$ \\
Focal length & 2 & $\mathrm{~m}$ \\
Parabola gab & 0.1 & $\mathrm{~m}$ \\
Distance between collectors & 15 & $\mathrm{~m}$ \\
Mirror material & glass & - \\
Mirror reflectivity & 0.96 & - \\
No of module/collector & 8 & $\mathrm{module}$ \\
No of collector/loop & 6 & $\mathrm{collector}$ \\
No of loop/field & 3 & loop \\
Total area for the loop & 10348 & $\mathrm{~m}^{2}$ \\
Diameter of Stainless steel tube & 0.066 & $\mathrm{~m}$ \\
Diameter of the glass cover & 0.119 & $\mathrm{~m}$ \\
Receiver tube absorptivity & 0.93 & - \\
\hline
\end{tabular}




\section{Modeling of the PTC}

The modeling of the PTC seeks to simulate the thermal performance of the collector at different operating parameters and different locations in Egypt. The thermal performance includes the incident solar energy, gained thermal energy, outlet temperature, the efficiency of the PTC, and the field efficiency. The modeling is based on the energy balance equation for the receiver tube components such as stainless steel absorber tube, the class cove, and the HTF. The energy model for the mirror and the receiver tube are shown in Fig. 2. The energy balance includes the incident Direct Normal Irradiation DNI on the collector, the optical losses from both the collector and the receiver tube, thermal losses from the receiver tube, and heat energy gained into the HTF. For a short receiver tube $(<5 \mathrm{~m})$ a one-dimensional energy balance gives reasonable results. All equations and relationships used for the reflector and the receiver tube models are described in the following section.

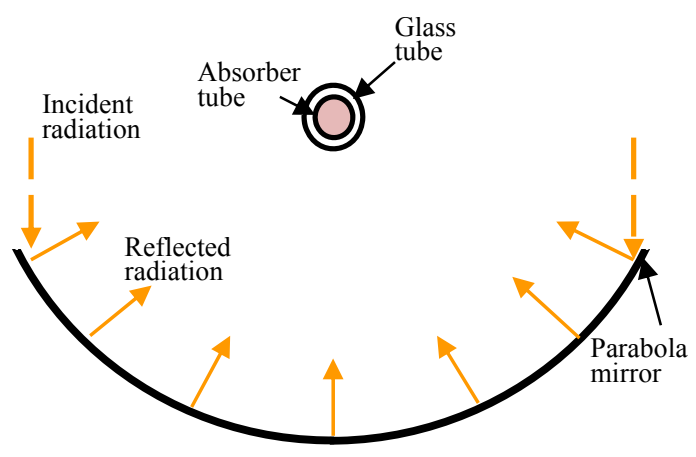

a)

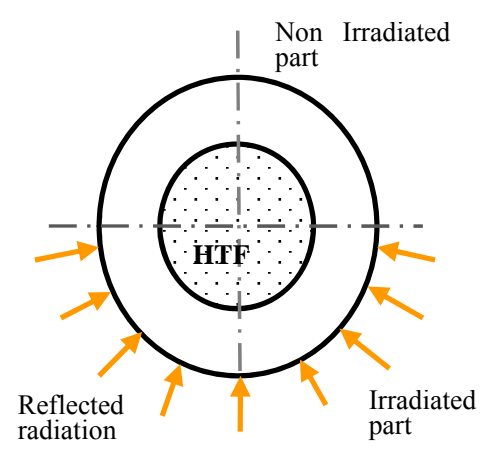

b)

Fig. 2. Schematic diagram of a) Parabolic trough collector b) Receiver tube

The solar energy reflected from the glass mirror is absorbed by the receiver tube. The quantity of solar energy absorbed $\mathrm{Q}_{\mathrm{ab}}$ by the HCE is obtained as follows

$$
\mathrm{Q}_{\mathrm{ab}}=\mathrm{DNI} \cdot \operatorname{Cos}(\theta) \cdot \mathrm{IAM} \cdot \mathrm{Ro}_{\mathrm{Sh}} \cdot \mathrm{En}_{\mathrm{Lf}} \cdot \eta_{\text {field }} \eta_{\mathrm{HCE}}
$$

Where IAM, Rosh, and En $\mathrm{L}_{\mathrm{Lf}}$ are the incident angle modifier, row shading factor, and the end losses factor, respectively. Parameters of the equation (1) are calculated in details through the numerical model. The energy balance equations for the $\mathrm{HTF}$, which is molten salt (a mixture of $60 \mathrm{wt} \% \mathrm{NaNO}_{3}$ and 40 wt $\% \mathrm{KNO}_{3}$ ), stainless steel absorber tube and the glass cover for irradiated zones are as follows:

$$
\begin{gathered}
\mathrm{h}_{\mathrm{c}, \mathrm{ms}} 2 \pi \mathrm{r}_{\mathrm{s}, \mathrm{i}}\left(\mathrm{T}_{\mathrm{s}, \mathrm{i}}-\mathrm{T}_{\mathrm{ms}}\right) \mathrm{dx}-\mathrm{h}_{\mathrm{c}, \mathrm{ms}} 2 \pi \mathrm{r}_{\mathrm{s}, \mathrm{i}}\left(\mathrm{T}_{\mathrm{ms}}-\mathrm{T}_{\mathrm{s}, \mathrm{i}}\right) \mathrm{dx} \\
-\mathrm{Q}_{\mathrm{i}}+\mathrm{Q}_{\mathrm{o}}=\mathrm{m}_{\mathrm{ms}} \mathrm{C} \mathrm{p}_{\mathrm{ms}} \frac{\partial \mathrm{T}_{\mathrm{ms}}}{\partial \mathrm{t}} \\
\left(\mathrm{Q}_{\mathrm{ab}}-\mathrm{Q}_{\mathrm{r}, \mathrm{s}, \mathrm{o}-\mathrm{g}, \mathrm{i}}\right) 2 \pi \mathrm{r}_{\mathrm{s}, \mathrm{o}} \mathrm{dx}-\mathrm{h}_{\mathrm{c}, \mathrm{ms}} 2 \pi \mathrm{r}_{\mathrm{s}, \mathrm{i}}\left(\mathrm{T}_{\mathrm{s}, \mathrm{i}}-\mathrm{T}_{\mathrm{ms}}\right) \mathrm{dx} \\
-\mathrm{Q}_{\mathrm{c}, \mathrm{s}(\mathrm{ir}-\mathrm{ni})} \mathrm{dx}=\mathrm{m}_{\mathrm{s}} \mathrm{Cp}_{\mathrm{s}} \frac{\partial \mathrm{T}_{\mathrm{s}}}{\partial \mathrm{t}} \\
\mathrm{Q}_{\mathrm{r}, \mathrm{s}-\mathrm{g}} 2 \pi \mathrm{r}_{\mathrm{s}, \mathrm{o}} \mathrm{dx}+\mathrm{Q}_{\mathrm{ab}, \mathrm{g}} \pi\left(\mathrm{r}_{\mathrm{g}, \mathrm{o}}^{2}-\mathrm{r}_{\mathrm{g}, \mathrm{i}}^{2}\right) \mathrm{dx}-\left(\mathrm{Q}_{\mathrm{c}, \mathrm{g}-\mathrm{am}}+\mathrm{Q}_{\mathrm{r}, \mathrm{g}-\mathrm{sk}}\right) \mathrm{dx} \\
-\mathrm{Q}_{\mathrm{c}, \mathrm{g}\left(\mathrm{ir} \_\mathrm{ni}\right)} \mathrm{dx}=\mathrm{m}_{\mathrm{g}} \mathrm{Cp} \mathrm{p}_{\mathrm{g}} \frac{\partial \mathrm{T}_{\mathrm{g}}}{\partial \mathrm{t}}
\end{gathered}
$$

The above heat balance equations for the steel tube and the glass cover are used for the non-irradiated zone. The Engineering Equation Solver EES software was used to solve the energy partial differential equation to calculate the temperature of the molten salt and the inner and outer temperature of the steel tube and the glass cover in the irradiated and non-irradiated zones.

The heat transfer coefficient between the receiver tube and the molten salt $h_{c, m s}$ is calculated based on the Nusselt number $\mathrm{Nu}$, the hydraulic diameter of the tube $\mathrm{Dh}$, and the thermal conductivity of the fluid $\mathrm{k}$ as presented in the following equations [17]:

$$
\begin{aligned}
& h_{c, m s}=\frac{N u k}{D_{h}} \\
& \mathrm{Nu}= \begin{cases}C_{1} \operatorname{Re}^{0.8} \operatorname{Pr}^{0.4} & , \operatorname{Re} \geq 2300 \\
C_{2} & , \operatorname{Re} \leq 2300\end{cases}
\end{aligned}
$$

$\mathrm{C}_{1}$ and $\mathrm{C}_{2}$ are two coefficients which depend on the receiver geometry. $\mathrm{Nu}, \mathrm{Re}$, and $\mathrm{Pr}$ are the Nusselt number, Reynolds number and Prandtl number of the fluid, respectively. The Reynold number is calculated as follows:

$$
\operatorname{Re}=\frac{\rho u D_{h}}{\mu}
$$

Where $\rho$ is the density of the HTF, $u$ is the velocity of the fluid inside the tube, and $\mu$ is the dynamic viscosity.

The selected locations in Egypt based on different latitude and climate so that four locations were selected. The four sites were selected as follows; one site in the north of Egypt (Borg Elarab) and two other sites in the middle of Egypt (Cairo, Asyut) and one site in the south (Aswan) the locations are shown in Fig. 3.

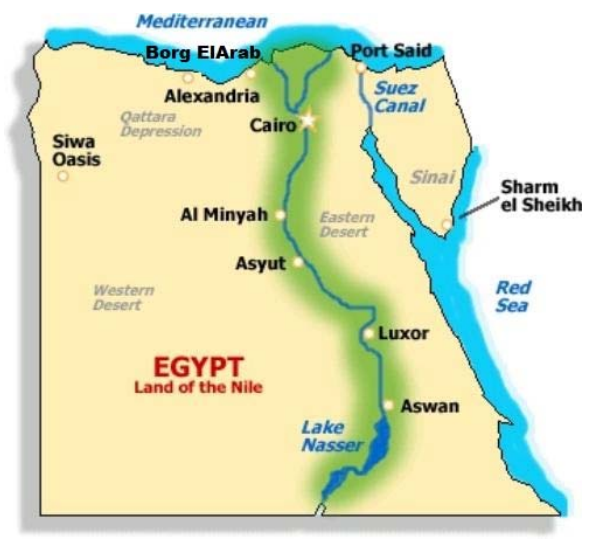

Fig. 3. Egypt map for the locations of the different selected sites 


\section{Results and Discussion}

Figure 4 shows the monthly Direct Normal Irradiance (DNI) for the selected locations in Egypt during the months of the year. We can observe that the lowest monthly DNI was in Borg Elarab through the winter months where the monthly DNI range from 128 to $179 \mathrm{KWh} / \mathrm{m}^{2}$ from Jan. to Mar., respectively. While, the Cairo site comes to the lower level through the summer months where it's monthly DNI ranges from 186 to $213 \mathrm{KWh} / \mathrm{m}^{2}$ from Apr. to Jun., respectively. The highest monthly DNI is found in two locations of the Upper Egypt, where the highest DNI was observed for Aswan through the winter months, where its monthly DNI ranges from 210 to 237 $\mathrm{KWh} / \mathrm{m}^{2}$. While Asyut comes with the highest level of the monthly DNI in the summer months where it's monthly DNI ranges from 189 to $223 \mathrm{KWh} / \mathrm{m}^{2}$. We can also observe a variation in the monthly DNI for the different locations during the whole year. The variation percentages for the selected locations are 53.4, 36.2, 31.4 and $4.5 \%$ for Borg Elarab, Cairo, Asyut, and Aswan, respectively.

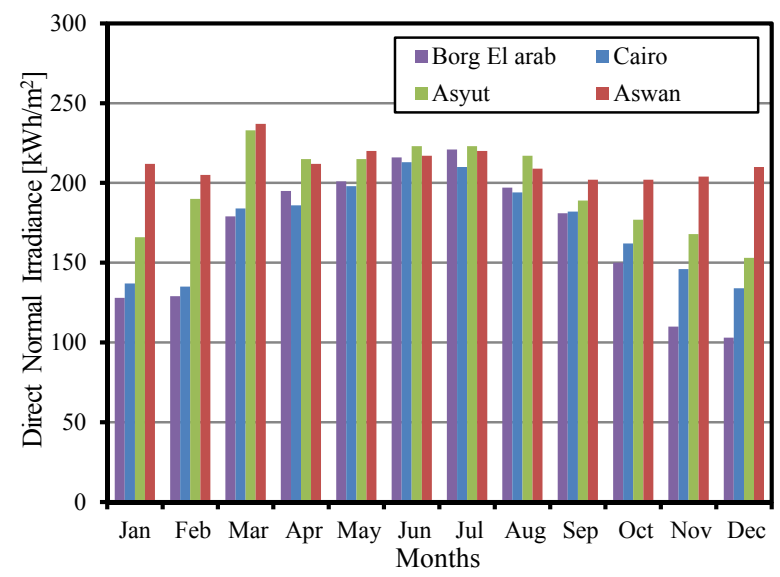

Fig. 4. Monthly direct normal irradiance (DNI) for different locations in Egypt.

The monthly thermal energy gained from the parabolic trough collector field for the selected locations in Egypt was presented for one year as shown in Fig. 5. We can observe a significant variation of the energy gained during the winter months and a smaller variation through the summer months. In the winter months, the difference in the energy gained between Aswan and Cairo sites ranges from 106.6 to 132.5 MWh for Jan. and Mar., respectively. In the summer months, this variation decays to a small value compared to the winter months, where it ranges from 53.2 to $82.8 \mathrm{MWh}$ for May and June, respectively. From Fig. 5 we can observe also that the highest energy gained through all the year come from the Aswan and Asyut locations. While the lowest energy gained was observed in Borg Elarab and Cairo locations.

Figure 6 presents the variation of the temperature rise of the HTF during a winter day for the selected regions. From the figure, it can be noticed that the temperature rise during a winter day varies from site to another where the highest temperature rise was observed in Asyut and ranged from 15 to $128{ }^{\circ} \mathrm{C}$. While the temperature rise in Borg Elarab was the lowest one and ranged from 8 to $111^{\circ} \mathrm{C}$. These changes may be attributed to the variation in the solar irradiance and the

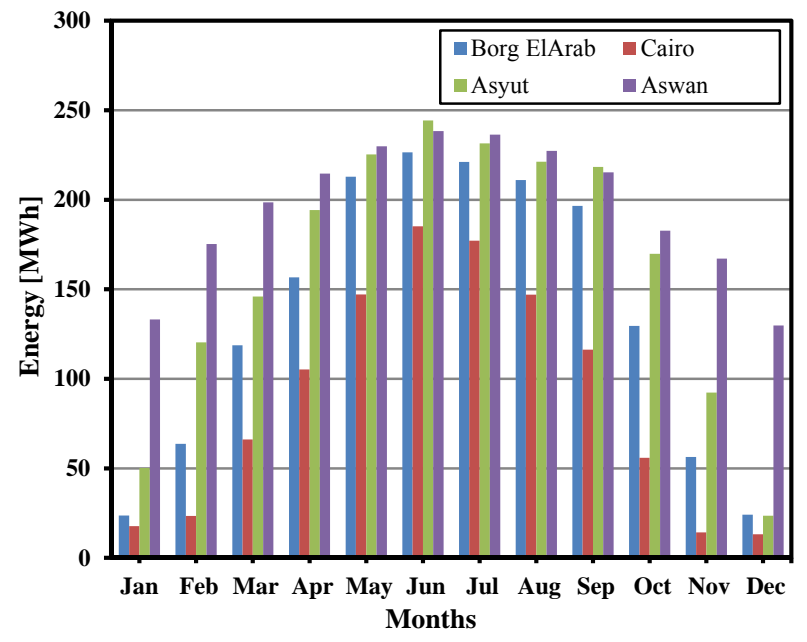

Fig. 5. The monthly energy gained from the solar concentrator filed for Borg ElArab, Cairo, Asyut, and Aswan

incident angle of the beam radiation among the selected regions and consequently the variation in the incident angle modifier IAM and the amount of the absorbed energy by the receiver tube.

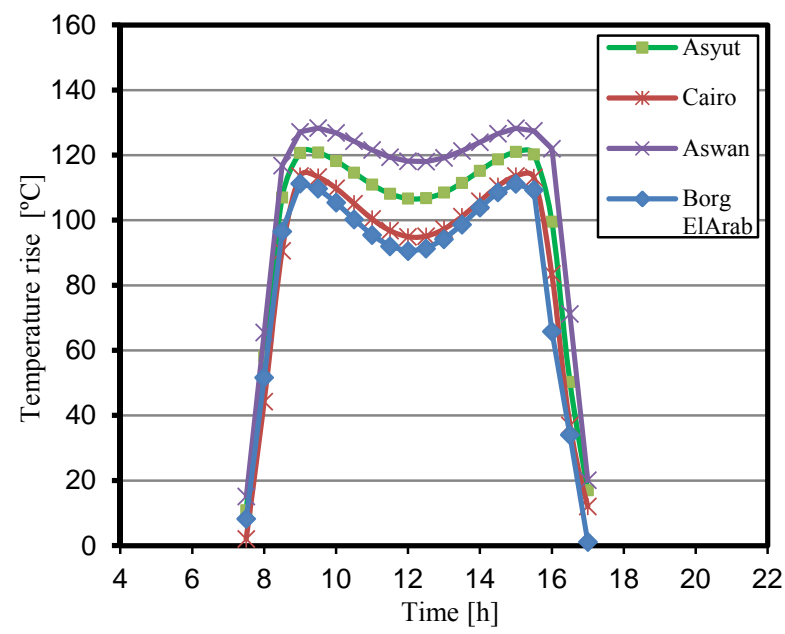

Fig. 6. The loop temperature rise in winter day (15 Jan) for selected locations.

For a summer day, the variation in the temperature rise among the selected regions can be neglected where difference doesn't exceed $4{ }^{\circ} \mathrm{C}$ at solar noon as shown in Fig. 7. This result is due to the small variances of the incident solar irradiance, especially at solar noon, among the selected regions. From the figure, we can observe a higher temperature rise for all regions compared to the winter day where the value of the temperature rise reaches $21{ }^{\circ} \mathrm{C}$ at solar noon where the maximum temperature rise is achieved two hours before and after the solar noon in the winter day as shown in Fig. 6. From figure 7 we can conclude that there is no big difference in the thermal performance for the four selected locations in summer.

The annual performance of the selected regions is presented in Table 2. The table shows that the maximum annual energy gained from the PTC is $14.35 \mathrm{GWh}$ and recorded in Aswan while the lowest value is $13.41 \mathrm{GWh}$ and recorded in Borg Elarab. The amount of the annual energy gained in Aswan increases by about $7 \%$ of the annual energy gained in Borg 


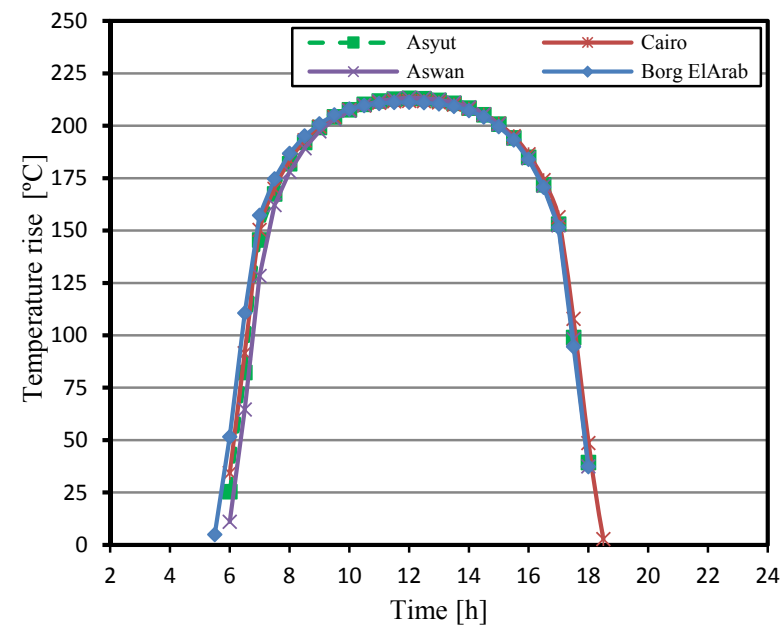

Fig. 7. The loop temperature rise in summer (15 June) day for the selected locations.

Elarab. The annual efficiency for the selected regions is nearly the same where their values range from 59.5 to $60.1 \%$.

The effect of the HTF mass flow rate on the outlet temperature of the PTC for the selected locations is presented for a summer and a winter day in Figures 8 and 9, respectively. The inlet
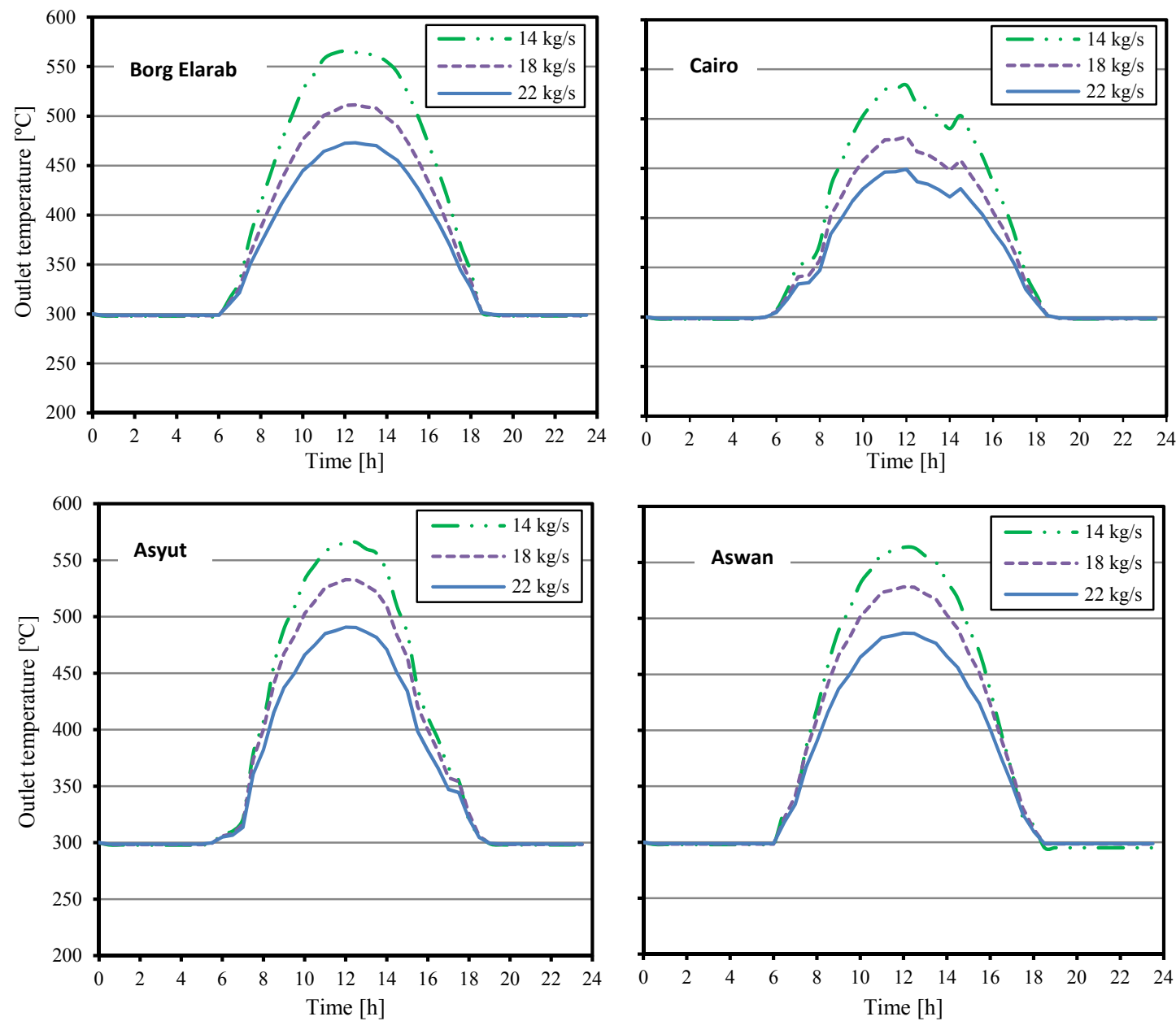

Fig. 8. The effect of mass flow rate on the PTC outlet temperature on a summer day (15 June) for all selected locations.

molten salt temperature is set to $300{ }^{\circ} \mathrm{C}$ for different flow rates and locations. Figure 8 presents the effect of the mass flow rate on the outlet temperature of the HTF at the selected locations on a summer day. From the figure, it can be observed that the lower outlet temperature of the HTF was in Cairo, where the outlet temperature ranges from 449 to $530{ }^{\circ} \mathrm{C}$ at solar noon for mass flow rate ranges from 14 to $22 \mathrm{~kg} / \mathrm{s}$, respectively. The high outlet temperature of the HTF was observed in Asyut, where the outlet temperature ranges from 490 to $565^{\circ} \mathrm{C}$ at solar noon for the same flow rate range. Some disturbances occurred in the output temperature profile of Cairo due to some clouds, humidity, and atmospheric dust, which led to the reduction of solar radiation at different periods.

Table 2. The annual energy incident and gained for the selected locations in Egypt

\begin{tabular}{llll}
\hline \multirow{4}{*}{ Location } & $\begin{array}{l}\text { Annual energy } \\
\text { output } \\
\text { GWH }\end{array}$ & $\begin{array}{l}\text { Annual incident } \\
\text { radiation } \\
\text { Borg El Arab }\end{array}$ & $\begin{array}{l}\text { Annual } \\
\text { efficiency }\end{array}$ \\
Cairo & 13.414 & 22.835 & $\%$ \\
Asyut & 13.555 & 22.538 & 59.5 \\
Aswan & 13.976 & 23.385 & 60.1 \\
\hline
\end{tabular}


Figure 9 presents the effect of the mass flow rate on the outlet temperature of the HTF at the selected locations on a winter day. From the figure, it can be observed that there is a decrease in the outlet temperature of the HTF in Borg Elarab site, where the outlet temperature ranges from 381 to $431{ }^{\circ} \mathrm{C}$ around solar noon for mass flow rate ranges from 14 to $22 \mathrm{~kg} / \mathrm{s}$, respectively, due to the presences of clouds in this area at this time of year. The high outlet temperature of the HTF was
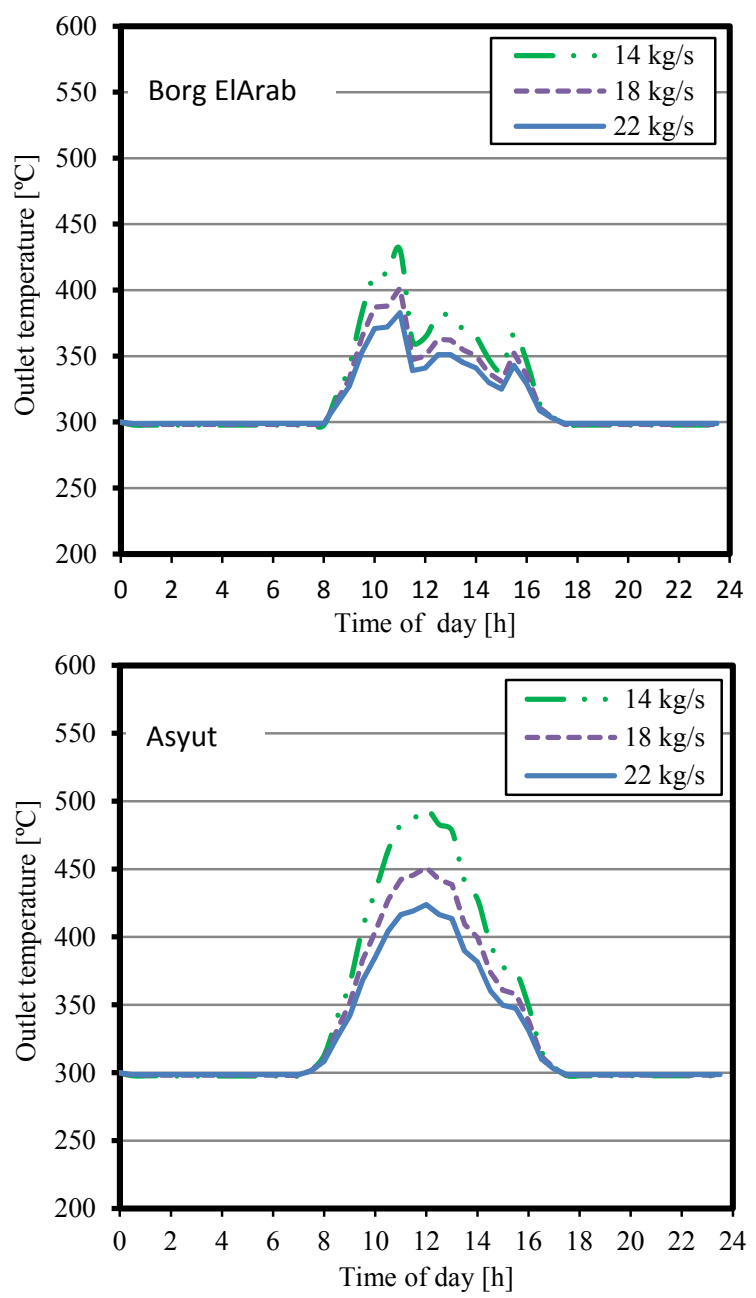

observed in Aswan, where the outlet temperature ranges from 442 to $522{ }^{\circ} \mathrm{C}$ at solar noon that can be attributed to the clear sky of Aswan in winter. The outlet temperature profile for Cairo has also some attenuation due to the presence of pollution, dust, and clouds in Cairo sky. The percentage increase in the outlet temperature for Aswan compared to Borg ElArab ranges from 16 to $21 \%$ at a flow rate varied from 14 to $22 \mathrm{~kg} / \mathrm{s}$, respectively.
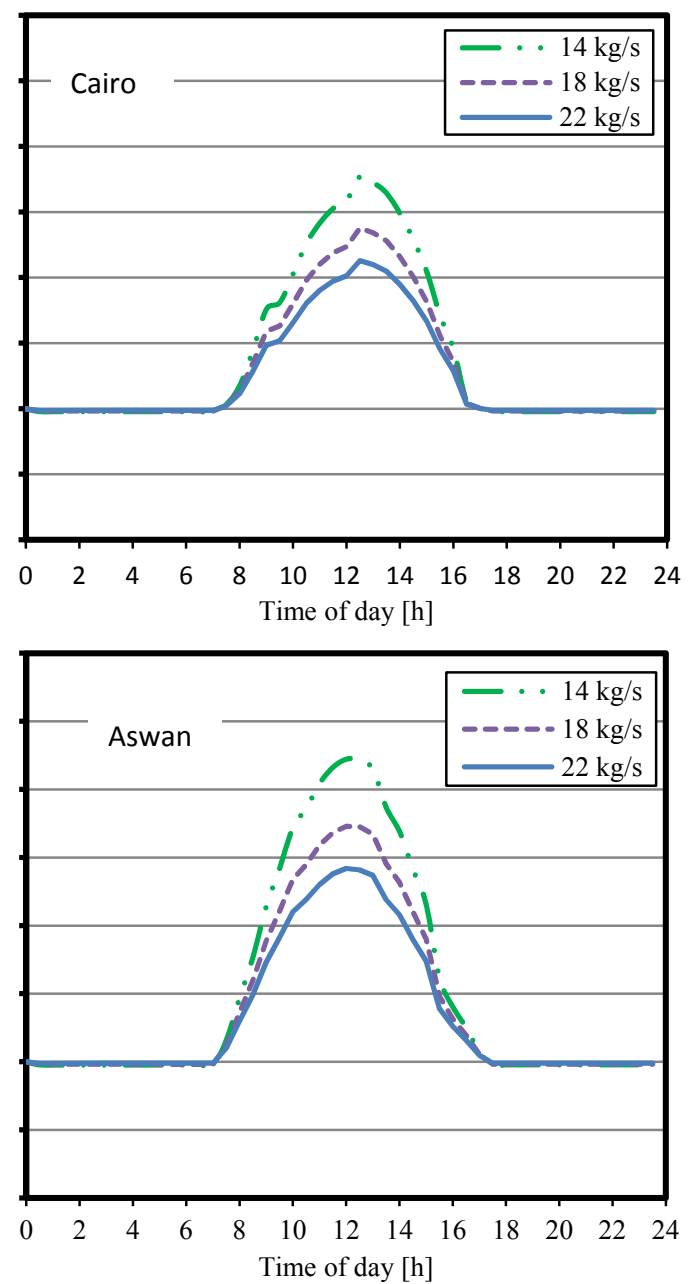

Fig. 9. The effect of mass flow rate on the PTC outlet temperature on a winter day (15 Jan.) for all selected locations.

The operating period for the parabolic trough concentrator is varied from season to another and from location to another. Figure 10 presents the operating period per week in the summer and winter for the different selected locations in Egypt. The operating period per week in summer was higher compared to winter for all selected locations and that can be attributed to the long day length in summer compared to winter. In the summer, it was observed that the longest operating period was in Borg Elarab and Aswan, where it reached about $82 \mathrm{~h} /$ week while the shortest operating period was observed in Cairo where it reached about $76.5 \mathrm{~h} / \mathrm{week}$. In the winter, the longest operating period was observed in Asyut and Aswan where it fluctuated around $60 \mathrm{~h} /$ week, while the shortest operating period was observed in Cairo and was 45 $\mathrm{h} /$ week.

For the validation of the PTC model, TRNSYS model was built to simulate the performance of the solar parabolic trough field.

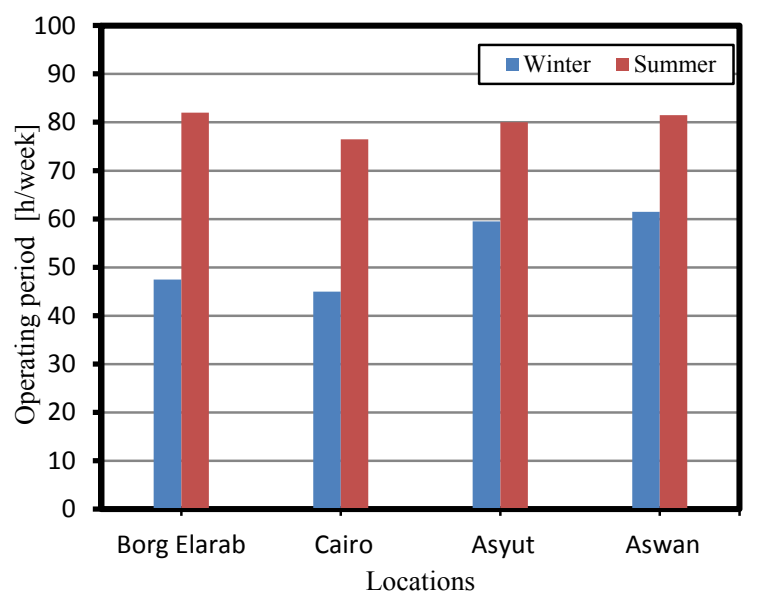

Fig. 10. The operating period of the PTC per week at the different selected regions 
Comparison between the results of the EES program and the TRNSYS software was presented in Fig. 11 for the different selected locations. Figure 11 presents the calculated energy gained from the PTC by the present model solved by the EES software and the calculated values from the TRNSYS Model.
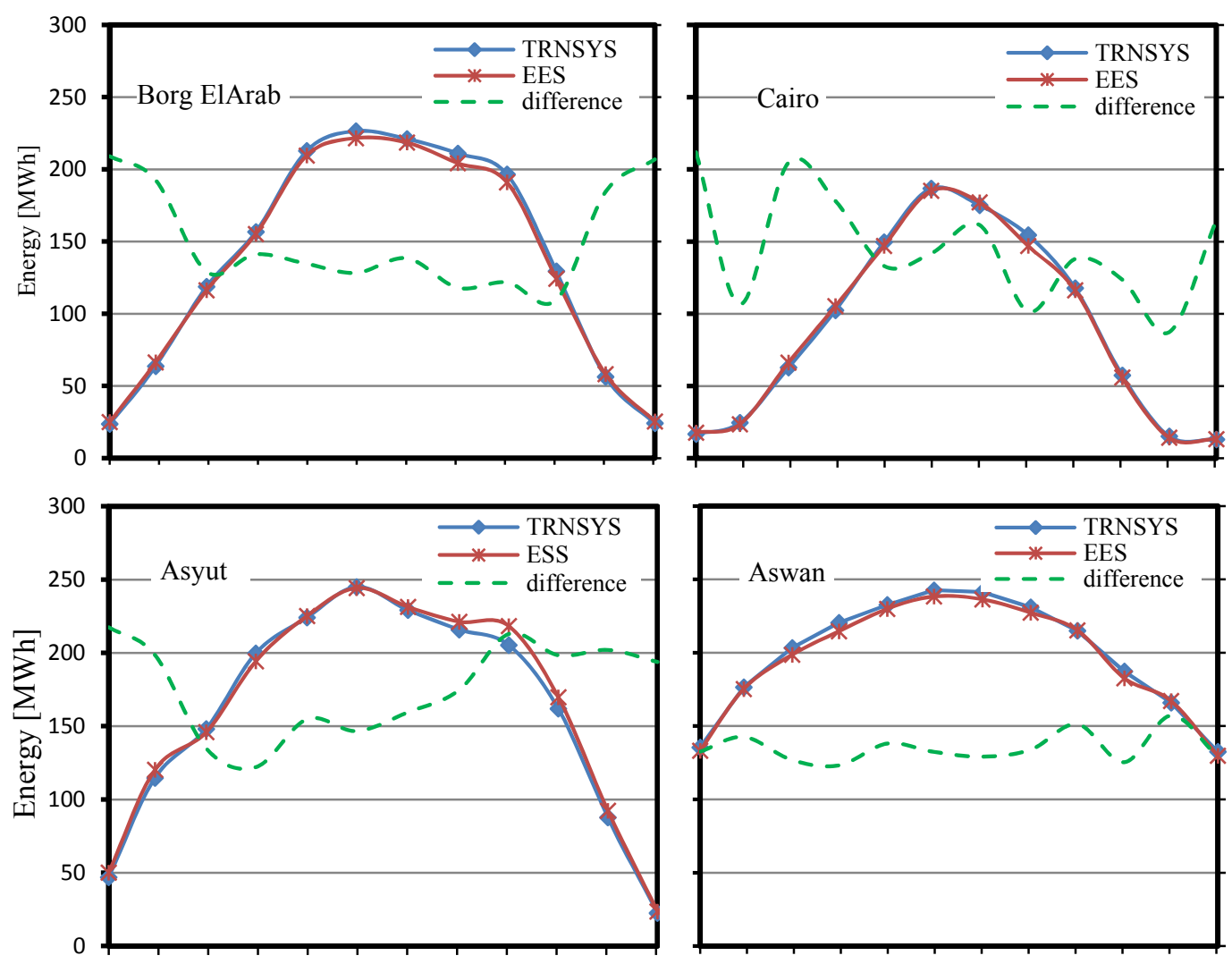

Jan Feb Mar Apr May Jun Jul Aug Sep Oct Nov D Months
$15 \%$

We can observe a significant compatibility between the result calculated from the EES program and the TRNSYS for all selected regions where the difference percentage between results from both programs doesn't exceed $\pm 5 \%$ refer to the values calculated from the present model.

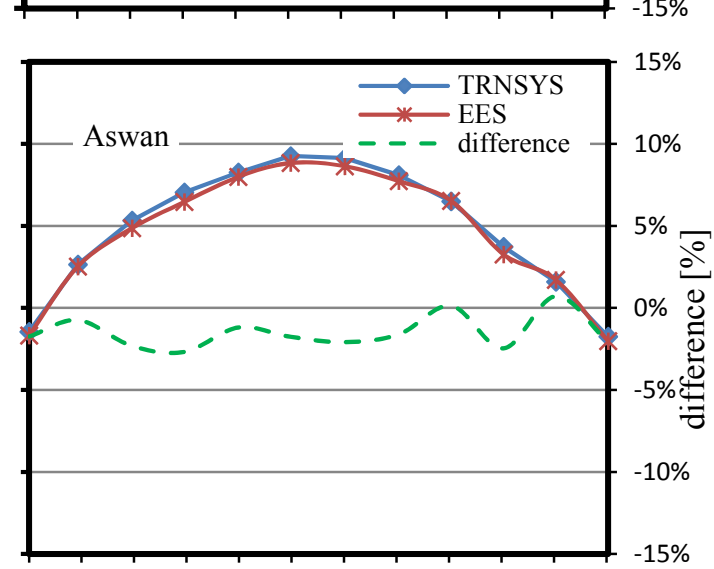

Jan Feb Mar Apr May Jun Jul Aug Sep Oct Nov Dec Months

Fig. 11. Comparison between the output results from the TRNSYS and EES programs for the energy gained.

\section{Conclusion}

This work presents a numerical model based on one dimension fluid flow. The EES software was used to solve energy equations of the receiver tube of the parabolic trough collector. A new design of the PTC that uses the molten salt as a HTF was considered in the model to elevate the outlet temperature up to $550{ }^{\circ} \mathrm{C}$. For solar power plant based on PTC erected in Egypt, four selected sites were tested. From the simulation program, we can conclude that Aswan comes as the best site where the annual DNI incident on $10600 \mathrm{~m} 2$ of concentrator aperture are was $23.86 \mathrm{GWh}$, and thermal energy gained from the same site was $14.35 \mathrm{GWh}$, which account $7 \%$ more than that gained from Borg ElArab site. The maximum temperature rise outlet temperature of the HTF was 211 and $565{ }^{\circ} \mathrm{C}$ respectively. In the summer, the maximum operating period of the PTC field was $82 \mathrm{~h} /$ week in Borg Elarab. While in the winter, the maximum operating period was $61.5 \mathrm{~h} /$ week in Aswan.

A significant compatibility between the result calculated from the present model and the TRNSYS model was achieved. So that the present model can be considered as a valuable tool for researchers and engineers to design and simulate the thermal performance of the PTC plant under different climate and locations.

\section{Nomenclature}

$\mathrm{Cp} \quad$ Specific heat, $\mathrm{J} / \mathrm{kg} \mathrm{K}$

D Diameter, $\mathrm{m}$

DNI Direct normal irradiance, $\mathrm{W} / \mathrm{m}^{2}$

h Heat transfer coefficient, $W / \mathrm{m}^{2} \mathrm{~K}$

m Mass, $\mathrm{kg}$

Q Heat energy rate, W

r Radius, $m$

T Temperature, ${ }^{\circ} \mathrm{C}$

t Time, $\mathrm{s}$

u Velocity, $\mathrm{m} / \mathrm{s}$

Greek Symbols

$\theta \quad$ Radiation incident angle

$\eta \quad$ Efficiency, \%

$\mu \quad$ Dynamic viscosity, $\mathrm{kg} / \mathrm{m} \mathrm{s}$

$\rho \quad$ Mass density, $\mathrm{kg} / \mathrm{m}^{3}$ 


\section{Subscripts}

$\begin{array}{ll}\mathrm{ab} & \text { Absorber } \\ \mathrm{am} & \text { Ambient } \\ \mathrm{c} & \text { Convection } \\ \mathrm{g} & \text { Glass cover } \\ \mathrm{h} & \text { Hydraulic } \\ \mathrm{i} & \text { Inner surface } \\ \mathrm{ir} & \text { Irradiated part } \\ \mathrm{ms} & \text { Molten salt } \\ \mathrm{ni} & \text { Nonirradiated part } \\ \mathrm{o} & \text { Outer surface } \\ \mathrm{r} & \text { Radiation } \\ \mathrm{s} & \text { Steel tube } \\ \mathrm{sk} & \text { Sky } \\ & \\ \text { Exponents } \\ \mathrm{C}_{1}, \mathrm{C}_{2} & \text { Coefficients } \\ \text { En } & \text { End loss factor } \\ \text { IAM } & \text { Incident angle modifier } \\ \mathrm{Rosh} & \text { Row shading factor } \\ & \\ \text { Non-dimensional Numbers } \\ \mathrm{Pr} & \text { Prandtl number } \\ \mathrm{Nu} & \text { Nusselt number } \\ \mathrm{Re} & \text { Reynolds number } \\ & \\ \mathrm{Nu}\end{array}$

\section{Acknowledgments}

This work was funded and supported by a grant from the European Union's Seventh Framework Program (FP7/20072013) and the Academy of Scientific Research and Technology (ASRT) through MATS project under grant agreement $\mathrm{n}$. 268219. The authors are grateful to the staff of the UTRINN unit of ENEA-Casaccia research center (Rome, Italy).

\section{References}

[1] A. Thomas. Simple structure for parabolic trough concentrator. Energy Conversion and Management, 1994;35:569-573, $\underline{8904(94) 90039-6}$ https://doi.org/10.1016/0196-

[2] M.W. Edenburn. Performance analysis of a cylindrical parabolic focusing collector and comparison with experimental results. Solar Energy 1976;18:437-444, https://doi.org/10.1016/0038-092X(76)90010-4

[3] J.A. Clark. An analysis of the technical and economic performance of a parabolic trough concentrator for solar industrial process heat application. International Journal of Heat Mass Transfer 1982;25:1427-1438, https://doi.org/10.1016/0017-9310(82)90136-3
[4] F. Lippke. Simulation of the part-load behavior of a 30 MWe SEGS plant. Sandia National Laboratories, Solar Thermal Technology Department, Albuquerque, New Mexico, 1995.

[5] A. Jones, R. Pitz-Paal, N. Blair, R. Cable. TRNSYS modeling of the SEGS VI parabolic trough solar electric generating system. Proceeding of Solar Forum 2001: Solar Energy: The Power to Choose, April 21-25, 2001.

[6] A.M. Patnode. Simulation and performance evaluation of parabolic trough solar power plants. M. Sc Thesis, University of Wisconsin Madison, USA; 2006.

[7] R. Forristall. Heat Transfer Analysis and Modeling of a Parabolic Trough Solar Receiver Implemented in Engineering Equation Solver. NREL/TP-550-169. NREL - National Renewable Energy Laboratory, Golden, Colorado; USA, 2003.

[8] N. Naeeni, M. Yaghoubi. Analysis of wind flow around a parabolic collector (1) fluid flow. Renewable Energy 2007;32:1898-1916.

https://doi.org/10.1016/j.renene.2006.10.004

[9] N. Fraidenraich, J.M. Gordon, D.E. Fernandes, R.d C. Lima. Improved solutions for temperature and thermal power delivery profiles in linear solar collectors. Solar Energy 1997;61:141-145, https://doi.org/10.1016/S0038092X(97)00049-2

[10] M.M. Rolim, N. Fraidenraich, C. Tiba. Analytic modeling of a solar power plant with parabolic linear collectors. Solar Energy 2009;83:126-133, https://doi.org/10.1016/j.solener.2008.07.018

[11] S. Bergmann, J. Rheinlander, M.R. Erbes. Transient performance modeling of a CSP plant with cascaded sensible and latent TES subsystems. SolarPACES, Granada, Spain, 2011.

[12] J. Spelling, M. Jocker, A. Martin. Annual performance improvement for solar steam turbines through the use of temperature maintaining modifications. Solar Energy 2012;86:496-504, https://doi.org/10.1016/j.solener.2011.10.023

[13] A.S. Tijani, M.S. Ashraf, B. Roslan. Simulation analysis of thermal losses of parabolic trough solar collector in Malaysia using computational fluid dynamics. Procedia technology https://doi.org/10.1016/j.protcy.2014.09.058

[14] S. Odeh, G. Morrison, M. Behnia. Modeling of parabolic trough direct steam generation solar collectors. Solar Energy 1998;62:395-406, https://doi.org/10.1016/S0038$\underline{092 X(98) 00031-0}$

[15] M.H. Ahmed. Two Dimension Numerical Modeling of Receiver Tube Performance for Concentrated Solar Power Plant. Energy procedia 2014;57:551-560, https://doi.org/10.1016/j.egypro.2014.10.209

[16] F.W. Dittus, L.M.K. Boelter. Heat Transfer in Automobile Radiators of the Tubular Type. International Communications in Heat and Mass Transfer 1930;12:322, https://doi.org/10.1016/0735-1933(85)90003-X 